\title{
The Growing Need of Netiquette in the Digital Age
}

\author{
Dr. Sonia Agarwal \& Dr. Manu Agarwal \\ Department of Humanities and Applied Sciences, AITH Kanpur
}

\begin{abstract}
Netiquette is a word which is combined from two words-Network and Etiquette. In fact it is a portmanteau word.With the growing importance and need for internet the world has been reduced into a global village. This is one of the benefits, but it has also made the communication into a very complicated process. The internet enlarges the vistas of human mind but has actually narrowed down the values of the human heart. In the existing global scenario the importance of netiquette has increased tremendously as the 'human' today is rarely divorced from technology. There has been an amazing transformation i.e. a Cyborg Ian shift of the human being. This paper is an attempt to address the issues related to etiquettes and the responsibilities required for networking.Despite the flow and exchange of information in various channels as Facebook,mailing,lists,blogs, forums and chats etc. the question still remains whether communication is taking place in all these forms in an effective manner.
\end{abstract}

Keywords: netiquette, Cyborg

\section{INTRODUCTION}

Technology has become indispensable for Humanity. Its pervasiveness insists that humans should use it optimally and discreetly. One should not become a slave of technology instead use it judiciously with maximum productivity. Today is the age of Cyborgs i.e. part humans and part machines. A term coined by Donna Harroway in Simians, Cyborgs, and Women(1991)Internet has really contracted the world into a "global village"- but communication has become a more complicated process. Despite the flow and exchange of information in various channels as Facebook, WhatsApp, blogs, forums, chats etc. the question arises whether communication in all these forms is taking place in an effective manner or not. So the Importance and growing need of netiquette .It simply means how a person should act while using digital technology online.

\section{MOBILE/CELL PHONE TECHNOLOGY}

Mobile phones have become the most common medium for communication both online and offline. The increasing use is because of its vast advantageous. Firstly it is mobile, hence can be carried anywhere without any hazels. Secondly, It saves time as it connects to an any person instantly. Thirdly, it helps to keep human contact intact. Fourthly, one can listen to songs, play games, email, video call, and message, take photos, calculate, check dates, time, etc. The android mobile phones are in fact mini computers on which you can do any sort of work that you do on a computer.It has become an integral and indispensable part of a human being.Mobile phones have made people Nomo phobic and they have become prisoners to their cell phones. Thanks to technology, we can now waste time with efficiency until now unimaginable, all in the name of saving time.

\section{ETIQUETTE IN TECHNOLOGY}

Etiquette is an umbrella term for rules governing socially and culturally accepted behavior. Etiquette in technology is a fairly recent concept. It is in fact a social code of network communication. The biggest challenge in the global scenario is communicating with others without any misunderstanding through the internet. The body language and facial expression cannot be interpreted in cyberspace. People misunderstand and lose precious relationship built for years by a casual click of the "send" button. The rules that apply when communicating over the internet are very different from those applying whencommunicating personally or through a telephone/mobile/videophone (skype video). It is in fact a social code of network communication.

Due to the increased flow and exchange of information in various channels as Facebook, mailing lists ,Blogs, Forums the question remains whether communication is taking place in all these forms in an effective manner or not. As a result, online communication guidelines called netiquette have been developed over the past few years. These informal guidelines called netiquette has become the need of the hour in the present scenario. People should be aware that their behavior impacts other people online. They should all strive to develop a positive and supportive environment and be courteous.

\section{NEED FOR NETIQUETTE}


Netiquette refers to the correct proper,polite acceptable,social,official,professional norms, behavioral patterns and expected decorum for using the internet or the cyber space for communication purposes.Many people feel less inhibited in online situations/talks than face to face communication. These increased senses of inhibitions sometimes leadpeople to use less than their usual sense of personal respect for each other in online communication.Despite the flow and exchange of information in various channels as Facebook, mailing lists,blogs,forums and chats, the question still remains whether communication in all these forms is taking place effectively or not. As a result, online communication guidelines have been developed over the past few years. These informal guidelines called netiquette have become the need of the hour in the present global scenario. People should be aware that their behavior impacts other people online. They should all strive to develop a positive and supportive environment and be courteous.

\section{CYBERBULLYING}

Cyberbullying is to bully a person through electronic communication. This is done by sending offensive messages of intimidating nature. Due to the increasing use of internet, cyberbullying has in fact become quite a problem. Children are especially reluctant to admit to being the victims of cyberbullying.With the increasing use of technology in our lives, cyberbullying can take various forms. It could be trolling, grieving, flaming, swatting, doxing, etc. It could take place through email forums, social media platforms, messaging services, chatrooms, gaming services etc. where people can communicate openly using digital space. To understand it better cyberbullying is harmful and deliberate communication which is carried out by one or multiple people through electronic digital devices like-tablets, mobile phones, computers, gaming consoles etc. Education and awareness are the prominent areas which empowers everybody with the necessary tools and knowledge to safely manage their own online activities. We all can be a prey to digital abuse in some way or other. As the advancements of technologies will continue to evolve we must take every opportunity to learn more about living safely and confidently in this new digital age.

\section{Some incidences of cyberbullying}

A boy named ULIA Maelly from Brazil was bullied digitally by his friends. The so called friends spread hate rumors about him on the net among other groups. This upset Ulia so much that he went into depression and lost his one year in studies.Another incident is about a boy named Thomas who was a very lively friendly and diligent boy. He used to communicate with his friends digitally for long hours. Slowly and gradually his behavior changed tremendously. He became rude and argumentative. One day he committed suicide by hanging on the fan. It was found that he was Cyberbullied to a great extent by his friends due to whom he took such a drastic step.

\section{REMEMBER before you-}

Facebook

Text

Twitter

THINK

$T=i s$ it true?

$H=i s$ it helpful?

$I=$ is it inspiring?

$N=$ is it necessary?

$K=i s$ it kind?

\section{Guidelines for Netiquette}

1. Firstly always think twice before you write as without the use of non-verbal's there are more chances of misinterpretations.

2. Treat all people the same way as you would while face to face. You should respect the dignity of the other person.

3. Avoid using all capital letters as it makes your message too loud for the receiver. It should be used only where required appropriately.

4. Always keep the content very relevant and purposeful.

5. Use appropriate grammar and structure whenever you message or email as less changes of misunderstanding.

6. Keep the human element in mind while sending messages as it will help you to avoid curt messages that will hurt the receivers' sentiments.

7. Use suitable words, smileys and emoticons to give human touch And personal appeal. 
8. Use abbreviations or acronyms which are commonly known and universally recognizable for e.g. AKA(also known as), ASAP(as soon as possible), BTW(by the way), CUL(see you later) FYIL(for your information), KIT(keep in touch) LOL(laughing out loud), SYS(see you soon), TYVM(thank you very much) etc.

9. To create a smile (-)you can simply type :)

10. Simple and appropriate emoticons and signs help to tell the receiver that you take care in communicating your message with the right tone and attitude.

11. One should always bear in mind consideration for the receiver which is one of the cardinal principle of netiquette.

12. Written words can be stored permanently hence one should be very careful in choosing the right word for communication.

13. Any mail sent very casually can return with so much malignity that the sender regrets throughout his or her life for having sent that one thoughtless mail. Ironically the receiver controls the sent mail so be careful.

14. Once your email/message has been sent, the receiver can use it against you and send it to numerous people, get a printout and post it on the public notice board thus put you to shame.

15. Be very ethically correct and in all circumstances avoid the saying "All is fair in cyberspace"

16. It is pertinent to be polite, clear, concise and courteous while on the internet.

17. Avoid spelling, grammar and typographical errors as they reflect illiteracy and lack of professionalism.

18. One should respect others time and bandwidth.

19. Always try to keep flame wars under control.

20. Be always forgiving of other people's mistakes.

21. Don't talk anything controversial i.e. about religion and politics.

If the rules and guidelines of netiquette are followed properly it could generate a high level of professionalism and likeability and thus result in getting favorable responses in internet based communication.

\section{CONCLUSION}

Communication is a very complex interactive process .It involves shared assumptions and unspoken agreement between individuals so frequent errors and misunderstandings are bound to happen. Communication has become very easy and quick. It is anytime, anywhere, and anyhow. You connect at the touch of a button. Due to advancements in technology the world has shrunk into a global village. As a result, the greatest need is to communicate effectively and responsibly following human values and netiquettes. Effective communication is a stepping stone to success.

"The difference between the almost right word and the right word is really a large matter-it's the difference between the lightning bug and lightning." Mark Twain

\section{REFERENCES}

[1] Shea.V, Netiquette,(1997)http://www.albion.com/netiquette/book/index.html

[2] Mossberger, Karen(2008),Routledge Handbook of Internet Politics. Routledge.pp.173185.ISBN0415780586.

[3] "What does digital citizen mean to you?"Microsoft.Retrieved 13 September 2013.

[4] Britland,Mike(26 August 2013). "How to teach...E-safety and Digital Citizenship." Guardian, Retrieved 13 September 2013.

[5] Ohler, Jason(2010),Digital Community, Digital Citizen. Corwin Press, ISBN1412971446.

[6] Loader,Brian (2007). Young Citizens in the Digital A. Routledge. pp.133-134. ISBN. 0203946723.

[7] Bebo White, Irwing King, Philip Tsang(2011), Social Media Tools and Platforms in Learning Environments Springer, pp.406-407, ISBN 3642203914.

[8] Karen Mossberger,Caroline J. Tolbert,William Franko(2012), Digital Cities: The Internet and the Geography of Opportunity, Oxford University Press. pp.64-65, ISBN. 0199812950

[9] Pregowski, Michalpiotr, "Rediscovering the Netiquette: the role of propagated values and personal patterns in defining self-Identity of the internet User." Observatorio 2009: 354-6.Google Scholar. Web. 15 Dec. 2010. http://obs.obercom.pt/index.php/obs/article/view/241/2488.

[10] Null, Christopher "Text messaging Etiquette: To text or Not to Text”PCworld.com.2010, Web. 15 Dec, 2010.

[11] External Links

[12] Software Reference Netiquette: Internet etiquette in the age of the blog \{extract),2009

[13] Toastmasters on Social Media Etiquette

[14] “A new sort of online protocol” CNET, 1997 (last accessed: 2014-01-17)

[15] Virginia SheaNetiquette(online ed.) book.

[16] RFC1855: the historical 1995 document at IETF, listing Netiquette guidelines. 